\section{\$24. Enhancement of Thermal Properties of HTS Magnets using Built-in Cryogenic Oscillating Heat Pipes}

Mito, T., Natsume, K., Yanagi, N., Tamura, H., Terazaki, Y.

Enhancement of thermal properties of high-Tc superconducting (HTS) magnets has been investigated using built-in cryogenic oscillating heat pipes (OHP). It is rather difficult for a HTS magnet to quickly remove the heat generated in windings, especially, in a protection operation when a magnet quenches, because the thermal diffusivities of component materials of windings decrease with an increase of temperature. Therefore, a local hot spot can be formed in a magnet, and there are possibilities of having degradation of superconducting properties and/or mechanical damages by thermal stresses. Fig. 1 shows a conceptual design of HTS magnets using the built-in cryogenic OHPs in order to improve the thermal properties of windings and to protect them from a damage caused by a large temperature gradient.

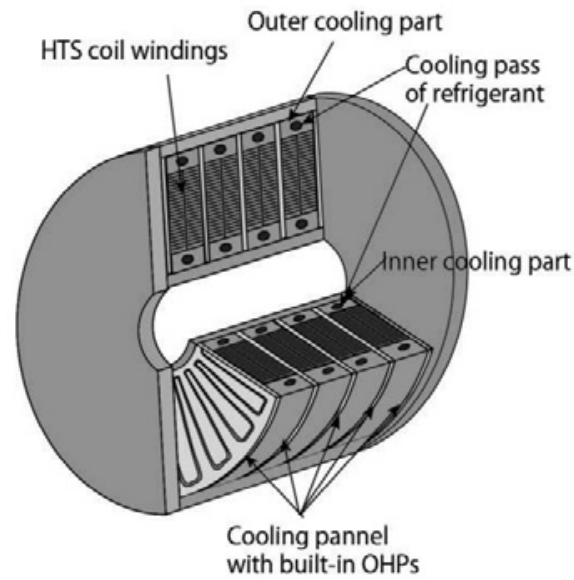

Fig. 1. Conceptual design of HTS magnets using the built-in cryogenic OHP.

In the previous studies, the proto-type cryogenic OHP has been used, which consists of an evaporator section and a condenser section both made of copper blocks, and stainless-steel pipes bent into many turns connect these sections. This simple structure of the prototype OHP was adequate to investigate the feasibility of cryogenic OHP, however, it is unsuitable to build-in OHP in magnet windings. ${ }^{1)}$

A flat-plate cryogenic OHP has been developed, that is suitable for imbedding in magnet windings as a high-performance heat transportation device in order to increase the thermal conductivity and the thermal diffusivity at the same time. ${ }^{2)}$ Fig. 2 shows the stainless steel base plates where the grooves were processed with the laser beam machine. Two base plates and upper and lower cover plates were assembled inserting Ni-based brazing filler metal sheets to which the channel grooves were processed by etching. The assembled flat-plate OHP was
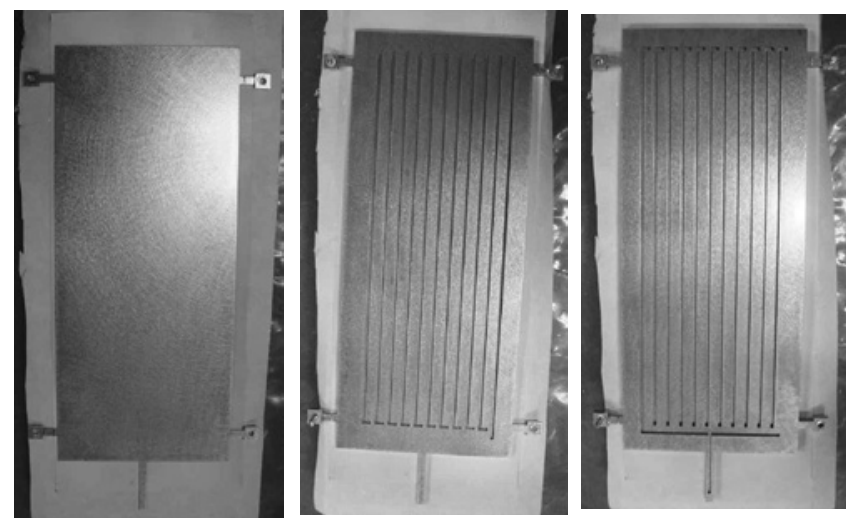

Fig. 2. Base plates with grooves and cover plate for the flat-plate OHP.

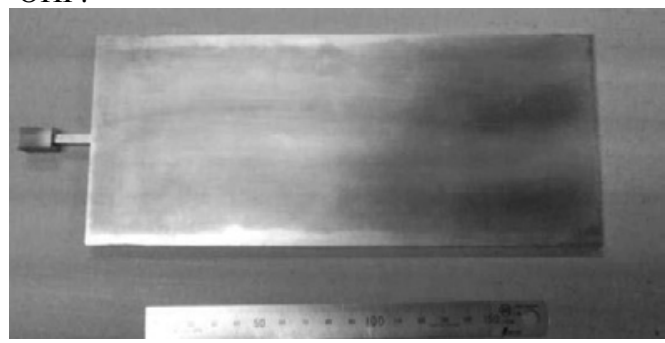

Fig. 3. Assembled and brazed flat-plate cryogenic OHP.

heated for brazing to about $1000 \operatorname{deg} \mathrm{C}$ in the vacuum furnace. Fig. 3 shows the completed flat-plate cryogenic OHP after brazing.

Stable operations of the cryogenic OHP within the wide operational ranges have been confirmed. In addition, it has been demonstrated to have high heat transport characteristics which surpass those of high-purity metals. Table 1 summarizes the measured thermal properties of the flat-plate cryogenic OHP.

Table 1. Thermal properties of the flat-plate cryogenic OHP

\begin{tabular}{cccc}
\hline \hline $\begin{array}{c}\text { Working } \\
\text { fluid }\end{array}$ & $\begin{array}{c}\text { Operating } \\
\text { temperature } \\
(\mathrm{K})\end{array}$ & $\begin{array}{c}\text { Filling rate of } \\
\text { liquid }(\%)\end{array}$ & $\begin{array}{c}\text { Effective thermal } \\
\text { conductivity } \\
(\mathrm{W} / \mathrm{m} \bullet \mathrm{K})\end{array}$ \\
\hline $\mathrm{H}_{2}$ & $18-24$ & $23-60$ & $\sim 850$ \\
$\mathrm{Ne}$ & $26-32$ & $23-53$ & $\sim 2500$ \\
$\mathrm{~N}_{2}$ & $79-84$ & $22-45$ & $\sim 3500$ \\
\hline
\end{tabular}

The flat-plate cryogenic OHP has been developed, which is suitable for the built-in OHP imbedding in HTS magnets. The test results using hydrogen, neon, and nitrogen as working fluids proved its excellent thermal transport properties with the effective thermal conductivities of $\mathrm{H}_{2}(850 \mathrm{~W} / \mathrm{m} \cdot \mathrm{K}), \quad \mathrm{Ne}(2,500$ $\mathrm{W} / \mathrm{m} \cdot \mathrm{K})$, and $\mathrm{N}_{2}(3,500 \mathrm{~W} / \mathrm{m} \cdot \mathrm{K})$ in the wide operating temperature range of $18-84 \mathrm{~K}$.

1) K. Natsume, et al, "Development of cryogenic oscillating heat pipe as a new device for indirect/conduction cooled superconducting magnets," IEEE Transactions on Applied Superconductivity, vol. 22, 2012, Page(s): 4703904.

2) T. Mito, et al., "Enhancement of Thermal Properties of HTS Magnets Using Built-in Cryogenic Oscillating Heat Pipes," IEEE Transactions on Applied Superconductivity, vol. 23, 2013, Page(s): 4602905. 